\title{
GEOGRAFIA FÍSICA ESCOLAR: TEORIAS E CONCEITOS, ESCALAS E LINGUAGENS
}

\author{
Francisco Nataniel Batista de Albuquerque ${ }^{(a)}$ \\ (a) Instituto Federal de Educação, Ciência e Tecnologia do Ceará - IFCE/ Campus Iguatu, natangeo@ hotmail.com
}

\author{
EIXO: GEOGRAFIA FÍSICA: CURRÍCULO, FORMAÇÃO E PRÁTICAS DE ENSINO
}

\begin{abstract}
Resumo
A Educação Geográfica e, mais especificamente, a Geografia Física Escolar coloca-se na interface entre os saberes acadêmico e escolar numa difícil relação entre teoria e prática, formação técnica e política e Geografia Física e Geografia Humana necessitando a construção de pontes metodológicas que superem as rupturas em busca de uma Geografia escolar unitária, porém, reconhecendo as especificidades dos processos naturais e suas formas de abordagem. Diante dessa realidade, o artigo propõe-se a discutir algumas questões centrais do ensino da Geografia Fisica na Educação Básica no tocante a relação entre teorias geográficas e teorias da aprendizagem, conceitos consagrados e ressignificados, além da abordagem das escalas de análise espacial e temporal, bem como as linguagens do ensino de Geografia que permeiam os currículos atuais do Ensino Médio.
\end{abstract}

Palavras-chave: Geografia Física; Teoria da Aprendizagem; Escala de Análise; Linguagem.

\section{Introdução}

A Educação Geográfica, Geografia Escolar ou Ensino de Geografia aqui tratados como sinônimos, embora suscite grandes questionamentos, coloca-se na interface entre os saberes acadêmico e escolar, integrando dimensões teórico-conceituais e técnico-instrumental para a efetivação do ensinar Geografia na perspectiva de uma formação histórico-crítica em relação às desigualdades socioespaciais e a relação da sociedade com os ambientes naturais.

Dessa forma, a ciência geográfica e, principalmente, a disciplina de Geografia assume na Educação Básica um papel de suma importância no entendimento da relação sociedade e natureza numa análise espacial e temporal multiescalar possuindo um desafio ainda maior, no caso do Brasil, em função da sua grande extensão territorial e vasta bio e sociodiversidade característica essencial nas abordagens de uma ciência de forte base empírica.

Soma-se ao contexto espacial, as dualidades e/ou dicotomias clássicas como Geografia acadêmica versus Geografia Escolar expressa nas lacunas e rupturas entre os saberes produzidos nas universidades e ensinados nas escolas, a formação técnica versus formação política pautadas na abordagem técnica e conteudista e a construção de uma efetiva cidadania, além da Geografia Física versus Geografia Humana, esta última o calcanhar de Aquiles da ciência geográfica, pois, na prática segundo Coelho (2001) a 
Geografia Humana permanece alheia à dinâmica da natureza, tanto quanto a Geografia Física à dinâmica da sociedade. Enquanto os geógrafos físicos se restringem a tentativas incipientes de incluir o ser humano ou a população (quase nunca a sociedade) nas suas interpretações, os geógrafos humanos, por sua vez, limitam-se a ver o ambiente como substrato físico, que é passivelmente transformado pela sociedade.

Muito embora defendamos uma Geografia unitária, de interfaces, de travessias por meio de pontes metodológicas, os fenômenos sejam eles de origem social ou natural possuem dinâmicas peculiares submetidos a fatores, processos e escalas de análise distintos. Dessa forma, a Geografia Física no ambiente escolar precisa ser debatida dentro do seu universo empírico e conceitual na sua interface com a Educação.

Diante desse universo empírico, o artigo propõe-se a discutir as nuances centrais da Geografia Fisica Escolar no tocante a relação entre teorias geográficas e teorias da aprendizagem, conceitos consagrados e ressignificados, além da abordagem das escalas de análise espacial e temporal, bem como as linguagens do ensino de Geografia que permeiam os currículos atuais do Ensino Médio.

\section{Estado da arte da pesquisa em Ensino de Geografia Física Escolar}

As pesquisas na área da Geografia Escolar assumem posição secundária no cenário da Geografia brasileira, pois, a maioria dos pesquisadores no campo da Geografia Escolar dedicam-se prioritariamente a outras temáticas em detrimento da área em questão. A exceção ocorre em alguns programas de pósgraduação em Geografia como o da Universidade Federal do Rio Grande do Sul (UFRGS), da Universidade Federal de Goiás (UFG), da Universidade Federal do Piauí (UFPI), da Universidade Federal da Paraíba (UFPB) e da Universidade de São Paulo (USP) que possuem linhas de pesquisa consolidadas na área, além de pesquisadores isolados distribuídos pelo país.

A consolidação recente das pesquisas em Geografia Escolar reflete o fato dos cursos de Geografia terem assumido no início deste século esse campo de pesquisa como componente curricular, antes restrito aos cursos de Pedagogia e/ou departamentos de Educação das instituições de ensino superior introduzindo uma mudança cultural ao assumir a Geografia escolar como nicho de discussão e pesquisa contribuindo para a formação dos professores de Geografia.

Com base nas pesquisas realizadas até o final do século XX, Cavalcanti (2002, p. 30) aponta as ideias motrizes que ganharam força e despontaram no ensino de Geografia no início deste século:

- $\quad$ O construtivismo como atitude básica do trabalho com a Geografia escolar; 
- A "geografia do aluno" como referência do conhecimento geográfico construído em sala de aula;

- $\quad$ A seleção de conceitos geográficos básicos para estruturar os conteúdos de ensino;

- A definição de conteúdos procedimentais e valorativos para a orientação das ações, atitudes e comportamentos socioespaciais.

No campo da Geografia Física Escolar as pesquisas são mais escassas, setoriais e restritas a proposição de práticas de ensino. Nesse contexto podemos destacar algumas pesquisas como as de Morais (2011) ao discutir de forma mais abrangente o ensino das temáticas físico-naturais na Geografia Escolar e com recortes temáticos, as pesquisas de Falconi (2004), ao propor a produção de material didático para o ensino de solos e Oliveira (2010) ao apresentar contribuições teórico-metodológica para o ensino de Geomorfologia. Na Cartografia Escolar destacam-se as pesquisas de Almeida $(2007$; 2011) ao abordar o processo de ensino-aprendizagem da representação gráfica dos fenômenos espaciais desde a alfabetização cartográfica até as novas linguagens e tecnologias.

Outro indicador que pode traduzir a baixa quantidade de pesquisas na Geografia Física Escolar é a formação dos autores dos livros didáticos de Geografia. Albuquerque e Falcão Sobrinho (2007), ao analisarem o conteúdo de Geomorfologia nos livros didáticos constataram a formação dos autores no campo da Geografia Humana como um dos aspectos para a redução dos conteúdos relacionadas às temáticas físico-naturais nos livros didáticos chegando ao absurdo do conteúdo de Geomorfologia ser abordado em dois parágrafos ou colocado em anexo segindo as orientações de Machado (1989, p. 106, negrito nosso):

“A título de sugestão, por que não colocar os mapas clássicos de paisagens naturais, caso se ache necessário, no apêndice ou na parte de leitura complementar, eliminando-se de vez o seu caráter de principalidade, dando-lhes o caráter de curiosidade?"

Carvalho (1989) complementa que o fato de conferir importância às províncias geológicas do Brasil, suas rochas, formação, evolução, etc. contribuem para engrossar o coro dos geólogos que reivindicam a introdução da Geologia como matéria curricular no $2^{\circ}$ grau. No mínimo, o não-reconhecimento da importância dos conteúdos de Geografia Física conduz a negação da própria gênese e evolução da ciência geográfica, e mais do que isso a negação de que no estudo das organizações espaciais os elementos naturais não participam de sua constituição, além de negar a existência de uma problemática ambiental multifacetada e global.

Segundo Leff (2006, p. 284, grifo nosso):

"as disciplinas mais profundamente questionadas pela problemática ambiental acabam sendo as ciências sociais e as ciências naturais mais próximas das relações entre sociedade e natureza, como a geografia, a ecologia e a antropologia". 
Diante desse contexto de rupturas e especializações da seara científica, em parte produto de uma crise de percepção nas palavras de Capra (1996), a Geografia é convidada ou "intimada" através de seu instrumental teórico e aplicado a responder aos desafios impostos pelas questões ambientais da atualidade, produto da relação sociedade-natureza em diferentes níveis espaciais.

\section{Ensino de Geografia Física: teorias e conceitos}

O objetivo da Geografia na Educação Básica segundo Cavalcanti (2002, p. 14) é formar o raciocínio espacial que não implica apenas em localizar, mas em compreender as determinações e implicações das localizações e, para isso são necessários referencias teórico-conceituais. A integração entre teorias geográficas e as teorias pedagógicas, especialmente, aquelas ligadas ao processo de ensino e aprendizagem são necessárias para compreensão da dinâmica espacial geográfica e a dimensão do processo de ensino-aprendizagem especialmente na Educação Básica.

Nesse contexto, duas teorias assumem grande importância, a Teoria Geral do Sistemas formulada por Ludwing von Bertalanffy na década de 1930 e a Teoria da Aprendizagem Significativa de David Paul Ausubel desenvolvida na década de 1960.

A Teoria Geral dos Sistemas (BERTALANFFY, 2010) largamente difundidade e consolidada em várias áreas do conhecimento assume na Geografia uma posição de âncora teórica ao fundamentar os métodos de análise geográfica de forma integrada e multiescalar. Segundo a Academia Española (1925 apud FUERTES, 2007, p. 117) sistema é uma palavra de origem latina que significa "conjunto de cosas que ordenadamente relacionadas entre sí contribuyen a determinado objeto". Bertalanffy $(2010$, p. 132), por sua vez, define sistema como uma "unidade global organizada de inter-relações entre elementos, ações e indivíduos".

Entre as premissas da TGS, principalmente as que regulam os sistemas abertos estão as seguintes características dos objetos (BERTALANFFY, 2010): são vistos como sistemas dentro de sistemas maiores; são sempre afetados por variáveis externas, apresentando um comportamento probabilístico; interdependência entre as partes (não é um sistema mecânico); capacidade de auto-regulação (permanência do sistema) e a adaptabilidade (ruptura e inovação); apresenta fronteira tênue e muitas vezes sobreposta na delimitação dos elementos internos e externos ao sistema; capacidade de se modificar, corrigir e de obter novos e melhores resultados; capacidade de superar perturbações impostas por fenômenos externos; esforço simultâneo de vários órgãos que provoca um resultado ampliado (sinergia); Na abordagem sistêmica, conforme Morin (2008, p. 156): 
[...] A explicação reducionista de um todo complexo nas propriedades dos elementos simples e nas leis gerais que comandam estes elementos também desarticula, desorganiza, decompõe e simplifica o que faz a própria realidade do sistema: a articulação, a organização, a unidade complexa".

O próprio aluno insere-se como elemento integrante de um sistema, no caso o educacional o qual necessita portanto, compreender que currículos, conceitos e práticas de ensino trabalhados, por exemplo, são partes de um todo (tendência integrativa), mas que precisa ser preservada sua autonomia individual, ou seja, suas experiências e anseios pessoais (tendência auto-afirmativa) configurando na prática a própria lógica de abordagem sistêmica onde os subsistemas possuem tendências opostas, porém complementares como ressalta Capra (1996).

Nesse contexto de auto-afirmação, ou seja, do respeito a compreensão de mundo do aluno colocam-se na mesa de discussão várias teorias da aprendizagem dentre as quais está a Teoria da Aprendizagem Significativa (MOREIRA \& MASINI, 2006), do psicólogo norte-americano David Ausubel. De acordo com Moreira \& Masini (2006, p. 07), a aprendizagem significativa é

"um processo pelo qual uma nova informação se relaciona com um aspecto relevante da estrutura de conhecimento do indivíduo. Ou seja, neste processo a nova informação interage com uma estrutura de conhecimento específica, a qual Ausubel define como conceitos subsunçores, existentes na estrutura cognitiva. A aprendizagem significativa ocorre quando a nova informação ancora-se em conceitos relevantes preexistentes na estrutura cognitiva de quem aprende"

Segundo a teoria de David Ausubel, o fator isolado mais importante para o aprendizado é aquilo que o aprendiz já conhece. Dessa forma, o professor deve pautar o processo de ensino-aprendizagem naquilo que já se conhece e no uso social do conteúdo remetendo ao que Cavalcanti (2002) chamou de "geografia do aluno" relacionando as aprendizagens aos conhecimentos pré-existentes dos sujeitos.

Para que a aprendizagem torne-se realmente significativa, 02 métodos de aprendizagem podem ser utilizados no processo de ensino-aprendizagem segundo Berbel (1998): a metodologia da Problematização e a metodologia da Aprendizagem baseada em Problemas (ABP). Enquanto na primeira, os problemas são identificados pelos alunos, a partir da problematização das características e contradições da realidade que os cercam, a segunda, é problematizada pelos professores ou pela escola obedecendo a uma sequência de problemas a serem estudados dentro de um currículo pré-estabelecido.

Com base nestes pressupostos teóricos surgem os conceitos geográficos e os esquemas mentais de entendimento dos mesmos. Os conceitos geográficos vão desde os clássicos como paisagem e região, até os menos difundidos e/ou utilizados no ambiente escolar como geossistema, domínio morfoclimático, 
recurso natural e específicos de regiões naturais como desertificação e arenização. Muito embora o repertório conceitual da ciência geográfica seja bastante vasto e de forte base empírica, na Geografia escolar o que se percebe é uma dificuldade em trabalhar alguns conceitos, os quais são discutidos pelo professor, geralmente, com base no senso comum ou reforçando conceitos de outras áreas como da Biologia.

A Geografia escolar explora os conceitos biológicos de bioma e ecossistema, ao invés dos conceitos geográficos de domínio morfoclimático (AB'SABER, 2003) e geossistema (SOTCHAVA, 1973; BERTRAND, 1972), os quais apresentam um base espacial e uma compreensão horizontal da paisagem. Nesse ponto de vista, os conceitos de região e paisagem devem fundamentar conceitos mais aplicados como domínio morfoclimático e geossistema, em detrimento, respectivamente, dos conceitos biológicos de bioma e ecossistema, não menos importante.

No tocante a ocupação dos ambientes naturais e exploração dos seus elementos, o conceito de recurso natural de forte relação sociedade-natureza permite discutir em sala a identificação dos recursos naturais regionais e seu processo de valoração e impactos ambientais, a partir das diferentes vivências dos alunos, os quais podem levantar os principais elementos e aspectos naturais apropriados como recurso natural na sua realidade.

A abordagem conceitual na sala de aula deve convergir para a busca da compreensão do movimento dos fenômenos, ou seja, da dinâmica e interação dos processos naturais superando a ideia de uma natureza morta e estática na busca pelo entendimento da dinâmica dos processos naturais compreendendo além das formas (noções puramente geométricas e altimétricas), os agentes, processos e materiais envolvidos no fenômeno compreendidos na devida escala espacial e temporal de sua ocorrência.

A discussão, embora complexa, pode ser introduzida em sala de aula através da análise comparativa (importante método da análise geográfica) com outros elementos de significância do cotidiano do aluno como, por exemplo, a fabricação de uma simples mesa de madeira. O referido objeto (forma), o qual é produto do trabalho de um marceneiro (agente) que ao dispor de materiais e ferramentas como madeira, serra e prego (materiais) executa o ato de serrar, pregar e lixar (processos) obtendo assim o produto final (forma) num determinado intervalo de tempo e espaço.

$\mathrm{Na}$ escala do tempo histórico marcada pela grande capacidade humana de transformação das paisagens, a ação antrópica surge como fator ativo na evolução da Terra. Nesse contexto, a Geografia Física Escolar precisa responder a seguinte questão: Qual a participação humana na dinâmica dos processos naturais da atualidade? Paisagens até então resultantes de processos exclusivamente naturais agora apresentam variações advindas da forte influência humana na apropriação dos sistemas naturais como são os casos dos 
solos (ex.: Antropossolos), feições de relevo (ex.: voçorocas), fenômenos climáticos (ex.: ilhas de calor e de frescor) e paisagens degradadas (ex.: desertificação/bad lands) até os efeitos do aquecimento global. Essa discussão acompanha as transformações na escala do tempo histórico como consequência da capacidade humana em transformar os ambientes naturais e que, portanto, precisa ser discutido além dos efeitos, a escala temporal humana na aceleração dos processos mesmo diante da dificuldade de abstração de fenômeos aparentemente estáticos e atemporais na compreensão de muitos alunos.

A compreensão conceitual, muitas vezes complexa, pode ser compreendida através de mapas conceituais como discute Tomita (2009) ao integrar visualmente segundo uma organização lógica do aluno as principais noções do conceito e a relação deste com outros conceitos permitindo ao aluno estabelecer conexões mentais entre os conteúdos abordados, principalmente, quando esse recurso didático está fundamentado em uma das metodologias de problematização da realidade possibilitando assim, uma aprendizagem significativa.

\section{Ensino de Geografia Física: escalas de análise e linguagens}

A análise espacial e temporal dos fenômenos geográficos coloca-se como condição básica à formação do raciocínio geográfico, assim como a compreensão da relação sociedade-natureza conferindo assim geograficidade ao fenômeno na compreensão de Abreu (2012). Dessa forma, os fenômenos embora resultantes de um conjunto de elementos integrados segundo a abordagem sistêmica ocorrem num determinado espaço e tempo, entedimento esse essencial no processo ensino-apredizagem, pois, quanto mais próximo à escala local e o tempo histórico mais significativa é a aprendizagem do aluno dada a capacidade de relação dos fenômenos com a escala/espaço de vivência.

No entanto, a compreensão da manipulação das diversas escalas como as do clima (RIBEIRO, 1993; MENDONÇA \& DANNI-OLIVEIRA, 2007), por exemplo, que interagem entre si considerando ao mesmo tempo os fenômenos da escala inferior como parte do todo, mas também com sua dinâmica individual ressaltando as duas tendências dos subsistemas naturais. A título de uma abordagem multiescalar na sala de aula, um aluno que vive em uma fazenda ou sítio que cultiva alimentos a partir de água dessalinizada do mar encravado nas bordas de uma cidade a sotavento de uma cordilheira (figura 1) precisa compreender como cada um desses fatores e recortes espaciais interagem para a construção do seu cotidiano rural atribuindo assim, significado aos conteúdos de geologia, geomorfologia e clima, por exemplo. 

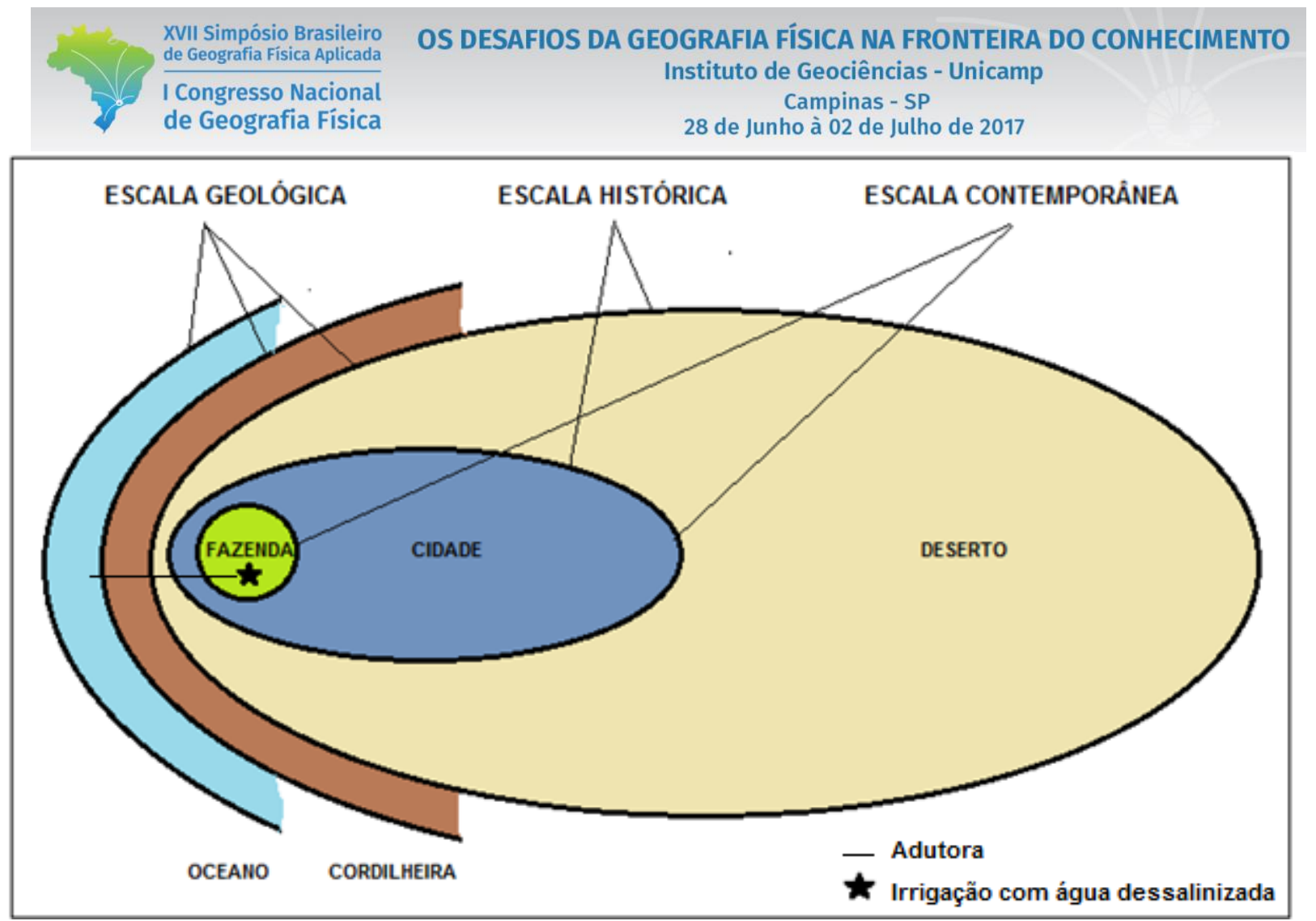

Figura 1 - Exemplo da abordagem integrada de escalas espaciais e temporais dos fenômenos.

O entendimento da escala de análise do fenômeno é importante, dentre outras coisas, para a compreensão das generalizações, faixas de transições e exceções existentes nas classificações temáticas das paisagens naturais, as quais do ponto de vista cartográfico são regiões rígidas e homogêneas. A classificação do relevo brasileiro proposta por Ross (1992), por exemplo, ao identificar planaltos, planícies e depressões gera um grau de generalização tão grande que, na escala local onde os alunos estabelecem a relação espacial fica difícil sua compreensão dificultando o entendimento que as feições de relevo podem ir de um pedestal ou pináculo (microforma), passando por uma duna e um inselberg até chegar a uma extensa cordilheira.

Nessa discussão, as áreas de exceção e as faixas de transição dos fenômenos naturais evidenciadas pelo domínios morfoclimáticos propostos por Ab'Saber (2003) refletem o entendimento real da dinâmica dos fatores naturais, diante das mudanças graduais e não-lineares na paisagem como por exemplo o contato Caatinga - Cerrado, além dos ambientes de exceção reflexos em parte de um jogo escalar, como é o caso da presença de plantas típicas de ambientes secos em paisagens atuais chuvosas e úmidas (figura 2) revelando além das exceções nas classificações genéricas, as escalas geológicas influenciando nas paisagens atuais. 


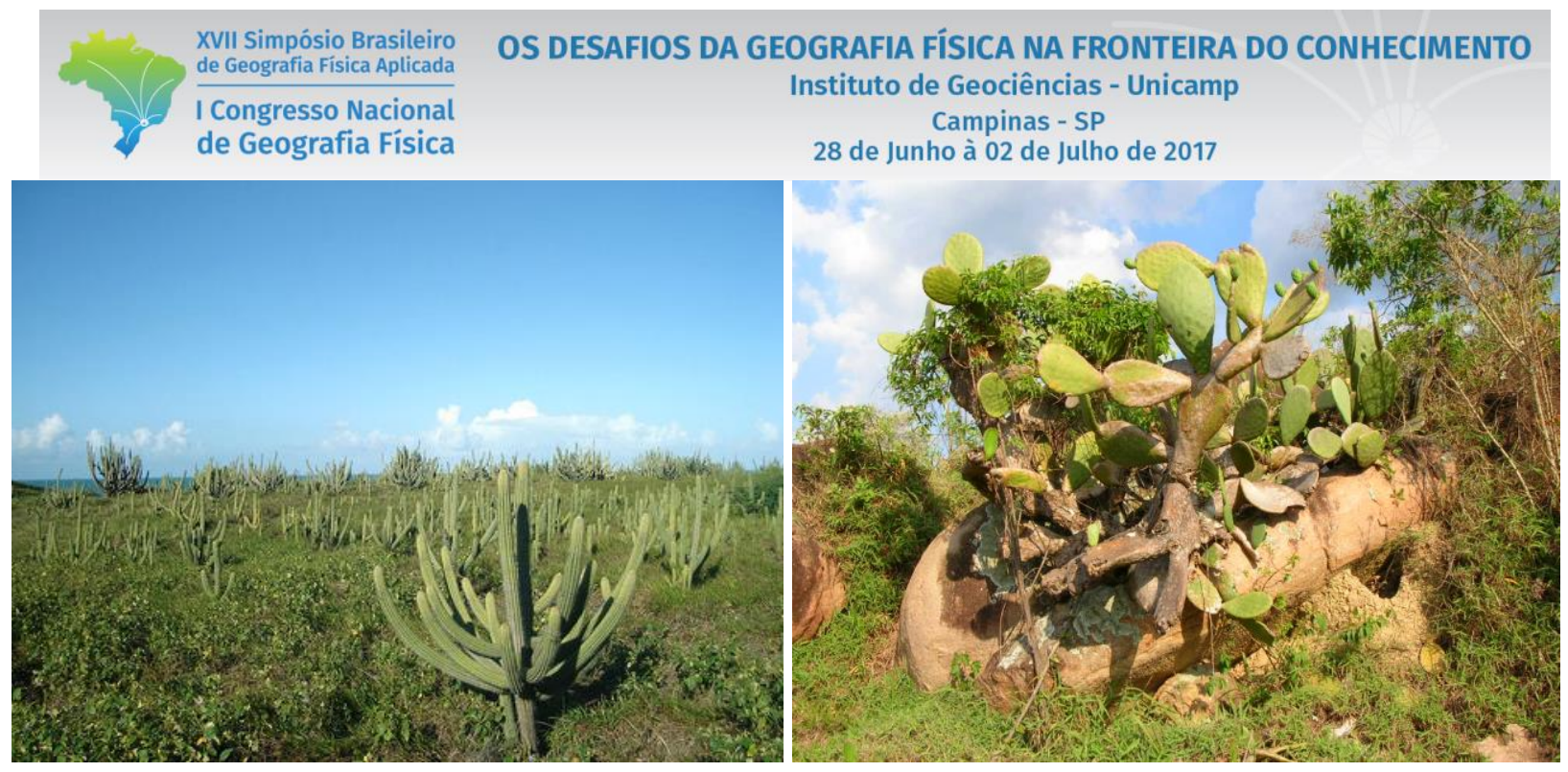

Figura 2 - Vegetação típica de ambientes secos na faixa de praia (Praia de Ponta Negra, Natal/RN) e na Depressão Periférica Paulista (Serra dos Cocais, Valinhos/SP).

O conhecimento geográfico (teorias, conceitos e escalas de análise) ocorre na prática mediante a utilização de diversas linguagens, sejam elas iconográficas, cartográficas e mídias e tecnologias digitais tendo ainda como principal recurso didático o livro didático, o qual se utiliza de varias dessas linguagens, especialmente, imagens e mapas.

No entanto, o livro didático de Geografia esbarra na padronização das paisagens brasileiras, em parte, decorrente da grande extensão e diversidade do território brasileiro e da necessidade de uma base curricular nacional comum. No caso específico da Geografia Escolar, essa questão assume um problema ainda maior, pois, a forte base empírica da ciência não permite a contemplação de domínios morfoclimáticos e geossistemas tão distintos pelos livros didáticos acarretando em generalizações e muitas vezes, equívocos. Dessa forma, a produção de material didático de apoio numa escala de maior detalhe se faz necessário, a fim do aluno discutir e compreender seu espaço de vivência.

Dentre as linguagens, o uso de imagens permite a realização de atividades de análise da paisagem por parte dos alunos através de métodos da comparação (semelhanças e diferenças), classificação, enquadramento temporal e espacial dos fenômenos e, mais do que isso, um exercício aguçado de análise integrada da paisagem, substituindo as enfadonhas provas objetivas propiciando uma mudança de paradigma do pensar Geografia, principalmente, diante da dificuldade logística e financeira das escolas em realizar trabalhos de campo.

As tecnologias e mídias digitais, por sua vez, permitem a compreensão da dinâmica dos fenômenos naturais, muitas vezes de uma forma lúdica e didática, permitindo pausas no movimento e uma explicação contextualiza. Dentre as tecnologias digitais estão os aparelhos celulares com GPS e sistemas de 
informação geográficos que permitem de forma interativa manipular informações de forma gratuita em sites.

A linguagem cartográfica, por sua vez, permite representar e analisar os fenômenos auxiliando na compreensão dos conteúdos, das escalas e generalizações/exceções das classificações. No entanto, uma questão central norteia a Cartografia no contexto escolar: A Cartografia é apenas um conteúdo escolar ou ferramenta metodológica geográfica? Sem sombra de dúvidas, a Cartografia Escolar configura-se como uma poderosa ferramenta de abordagem dos conteúdos e de formação do raciocínio geográfico devendo perpassar, portanto, todo o processo de ensino-aprendizagem geográficos.

\section{Conclusões}

A Geografia Física Escolar de pouco debate no meio acadêmico precisa superar a abodagem pragmática e setorial focada apenas nas práticas de ensino e discutir as teorias geográficas e as teorias da aprendizagem que conferem o arcabouço aos conceitos geográficos e ao processo de ensino-prendizagem dos alunos debatendo noções importantes como as escalas de análise dos fenômenos geográficos suscitando assim, a produção de novos paradigmas e recursos didáticos com maior grau de interatividade, principalmente no campo das tecnologias digitais de fácil apropriação pelos alunos fora da escola e tão pouco usado pela Geografia Escolar e pela Educação Básica.

Do ponto de vista teórico-conceitual, os mapas conceituais colocam-se como ótimos recursos gráficos de articulação das noções geográficas, pois, possibilitam a construção de esquemas mentais construídos por cada aluno. Da mesma forma que, do ponto de vista escalar e da linguagem geográfica, a Cartografia funciona como uma linguagem sintetizadora e dinâmica da discussão de escala de análise e cartográfica de suporte a qualquer conteúdo geográfico.

\section{REFERÊNCIAS}

ABREU, A. A. A paisagem e a Geografia. In: Palestra no V Seminário de Pesquisa em Geografia Física SEPEGE 2012. São Paulo: FFLCH/SUP. 2012.

AB'SABER, A. N. Os domínios de natureza no Brasil: potencialidades paisagísticas. São Paulo: Ateliê Editorial. 2003.

ALBUQUERQUE, F. N. B; SOBRINHO FALCÃO, J. A geomorfologia do semi-árido brasileiro nos livros de geografia do ensino médio: agentes, processos morfogenéticos e formas de relevo. Revista 
Homem, Tempo e Espaço. Sobral (CE), $\mathrm{n}^{\mathrm{o}}$ 1, setembro de 2007. Disponível em http://www.uvanet.br/rhet/artigos/art_geomorfologia_semiarido_fj.pdf

ALMEIDA, R. D. Cartografia escolar. São Paulo: Contexto. 2007.

(org.). Novos rumos da Cartografia Escolar: currículo, linguagem e tecnologia. São Paulo: Contexto. 2011.

BERBEL, N. A N. Problematização e a aprendizagem baseada em problemas. In: Interface Comunicação, Saúde, Educação. v. 2, n. 2, 1998. p. 139-154.

BERTALANFFY, L. Teoria geral dos sistemas - fundamentos, desenvolvimento e aplicações. 5. Ed. Petrópolis: Vozes. 2010.

BERTRAND, G. Paisagem e Geografia Física global: esboço metodológico. São Paulo, Instituto de Geografia. USP. 27 p. 1972. (Cadernos de Ciências da Terra, 13).

CAPRA, F. O ponto de mutação. 1996. 25. ed. São Paulo: Cultrix. 1996.

CARVAlHO, M. B. (1989). A natureza na Geografia do Ensino Médio. In: OLIVEIRA, A. U. de (org.). Para onde vai o ensino de Geografia? São Paulo: Contexto. p. 81-108. (Coleção repensando o ensino).

CAVALCANTI, L. S. Geografia e práticas de ensino. Goiânia: Alternativa. 2002.

FALCONI, S. Produção de material didático para o ensino de solos. Dissertação (Mestrado em Geografia) - Universidade Estadual Paulista, Instituto de Geociências e Ciências Exatas, 115 f. 2004.

LEFF, E. Racionalidade ambiental: a repropriação social da natureza. Trad. Luís Carlos Cabral. Rio de Janeiro: Civilização Brasileira, 2006.

MENDONÇA, F; DANNI-OLIVEIRA, I. M. Climatologia: noções básicas e climas do Brasil. São Paulo: Oficina de Textos. 2007.

MORAIS, E. M. B. As temáticas físico-naturais nos livros didáticos e no ensino de Geografia. Revista Brasileira de Educação em Geografia, v. 4, p. 175-194-194, 2014. 
MOREIRA, M. A; MASINI, E. F. S. Aprendizagem significativa: a teoria de David Ausubel. São Paulo: Centauro. 2006.

MORIN, E. O método - a natureza da natureza. 2. ed. Porto Alegre: Sulina. 2008.

OLIVEIRA, A. O. S. A. Contribuição teórico-metodológica para o ensino de Geomorfologia. Tese (Doutorado em Geografia) - Universidade Estadual Paulista, Campus Presidente Prudente. 2010.

RIBEIRO, A. G. As escalas do clima. Boletim de Geografia Teorética, 23 (45-46): 288-294, 1993.

ROSS, J. L. S. O registro cartográfico dos fatos geomórficos e a questão da taxonomia do relevo. In: Revista do Departamento de Geografia. São Paulo. FFLCH/USP. 1992. P. 17-29.

SOTCHAVA, V. B. O estudo do geossistema. Trad. MONTEIRO, C. A. F.; ROMARIZ, D. A. São Paulo: IG-USP. 1977.

TOMITA, L. M. S. Ensino de Geografia: aprendizagem significativa por meio de mapas conceituais. Tese (Doutorado em Geografia) - Faculdade de Filosofia, Letras e Ciências Humanas, Universidade de São Paulo, São Paulo. 183 f. 2009.

VENTURI, L. A. B. Recurso natural: a construção de um conceito. Revista GEOUSP - Espaço e Tempo. São Paulo. n. 20. 2006. pp. 09-17. 